American Journal of Immunology 8 (2): 52-64, 2012

ISSN 1553-619X

(C) 2012 Science Publications

\title{
Cell-Based Therapies in the Prevention of Solid Organ Transplant Rejection
}

\author{
${ }^{1}$ Adrian E. Morelli and ${ }^{2}$ Sherrie J. Divito \\ ${ }^{1}$ Department of the Surgery, Thomas E. Starzl Transplantation Institute, \\ University of Pittsburgh, Pittsburgh, Pennsylvania \\ ${ }^{2}$ Department of Medicine, Brigham and Womens Hospital, \\ Harvard Medical School, Boston, Massachusetts
}

\begin{abstract}
Problem statement: Organ transplantation is a life-saving and increasingly common procedure, as it often serves as the only treatment available for end-stage organ disease. Although the constant development of new and more effective immunosuppressive drugs has revolutionized the prevention and treatment of acute graft rejection, these drugs have significant toxicity, greatly increase patient susceptibility to neoplasms and infection and exert little impact on chronic rejection. Approach: The literature was reviewed to illuminate the mechanisms by which the anti-donor immune response is initiated and how cellular therapies impact this response. Results: Data show that Donor Specific Transfusion, Apoptotic Cell therapies and Dendritic Cell therapies all function as a source of alloantigen to suppress the anti-donor $\mathrm{T}$ cell response. Conclusion: Cellular therapies hold promise in the prevention of solid organ allograft rejection, but require optimization and study in large animal models before clinical implementation.
\end{abstract}

Key words: Ag-Presenting Cells (APC), Donor Specific Transfusion (DST), Dendritic Cells (DC), Apoptotic Cell Therapy, allograft, transplant rejection

\section{INTRODUCTION}

Organ transplantation is becoming an increasingly important and common surgical procedure, as transplantation surgery often serves as the only life-saving treatment available for end-stage organ disease. Although the constant development of new and more effective immunosuppressive drugs along with better knowledge of their therapeutic application have revolutionized the prevention and treatment of acute graft rejection, these drugs have significant toxicity and greatly increase patient susceptibility to malignant neoplasias and infections. Further, the implementation of immunosuppressive agents has exerted little impact on the incidence of chronic rejection and therefore overall long-term graft survival has only improved modestly. Novel cell-based therapies that are able to down-regulate the immune response against donor Antigen (Ag), without inducing generalized immune suppression and its harmful side-effects, represent a promising avenue of research in transplantation. Cellbased therapies include Donor Specific Transfusion (DST) (the transfusion of donor peripheral blood mononuclear cells), donor-derived apoptotic cell therapy and negative immunization with donor- (or recipient-) derived Dendritic Cells (DC). DC-based therapies in particular have received significant attention over the past decade as possibly ideal therapeutics in transplantation. Recent data though have shown that DC-based therapy, like DST and apoptotic cell-based therapies all function via a similar mechanism, that is as a source of alloantigen for presentation by recipient Ag-Presenting Cells (APC) to T cells.

Basics of solid organ transplantation: Allografts are grafted organs/tissues/cells transplanted between genetically disparate, MHC-mismatched individuals of the same species. The targeted $\mathrm{Ag}$ are called alloantigens (alloAg), are derived from Major Histocompatibility Complex (MHC) or minor histocompatibility $\mathrm{Ag}$ and are recognized by the adaptive immune response as non-self, or tissue incompatible (Afzali et al., 2007). Allo-recognition describes recognition of the allogeneic $\mathrm{Ag}$ by the recipient immune system and allo-response refers to the effector mechanisms recruited in the reaction to the transplanted cell/tissue/organ (Afzali et al., 2007).

Allografts are threatened by three types of rejection that are defined by both tempo of onset and histopathology. Hyperacute rejection occurs within minutes to h (usually within $48 \mathrm{~h}$ ) after transplantation surgery and is mediated by deposition of pre-formed circulating antibodies against $\mathrm{Ag}$ on graft vascular endothelial cells and the consequent activation of

Corresponding Author: Sherrie J. Divito, Department of Medicine, Brigham and Womens Hospital, Harvard Medical School, Massachusetts, MA 02115, Boston 
complement and coagulation cascades, resulting in intravascular thrombosis, ischemia and necrosis. This results from pre-sensitization of the recipient, by previous blood transfusion, organ transplant, or pregnancy and in $1 \%$ of the general population for no known reason. Hyperacute rejection is largely preventable due to screening for antibodies against nonself HLA phenotypes and cross-matching, with subsequent pre-transplantation plasmaphoresis if necessary (Gallon et al., 2002; Magee, 2006).

Acute rejection begins within weeks or months (5 days to 3 months is typical), or in rare cases even years, following transplantation and constitutes the main immediate threat to allograft survival. It is mediated by both innate and adaptive immune responses, however the advent of immunosuppressive drugs renders acute rejection largely preventable. Histopathology reveals diffuse interstitial infiltrate of $\mathrm{CD} 4^{+}$and $\mathrm{CD} 8^{+} \mathrm{T}$ cells with activated or memory phenotype (Ibrahim et al., 1995).

Chronic rejection develops in months or typically years post-transplantation and is the most common cause of graft loss one year after transplantation (Pascual et al., 2002; Sayegh and Carpenter, 2004). It results from both immune and non-immune factors. Typical features of chronic rejection include steady decline of organ function, interstitial fibrosis, chronic inflammatory infiltrate (i.e., lymphocytes, plasma cells), atrophy and gradual loss of parenchymal cells and chronic vascular arteriopathy, the latter a condition manifested by endothelitis, intimal proliferation, elastic fiber disruption, fibrosis and leukocyte infiltration of medium- and smallsize arteries of the graft (Pascual et al., 2002). Unfortunately, current immunosuppression protocols are ineffective at preventing or treating chronic rejection.

The development and introduction of immunosuppressive drugs in the 1980s has greatly reduced the risk of acute rejection. Steroids, calcineurin inhibitors such as tacrolimus and cyclosporine that block TCR-dependent $\mathrm{T}$ cell activation, the MTOR inhibitor sirolimus, mycophenylate mofetil which inhibits purine biosynthesis and lymphocyte-depleting antibodies are currently employed in the clinic to prevent or mitigate acute rejection with great success. However, these agents non-specifically suppress the immune system, thus greatly increasing patient susceptibility to opportunistic infections and various cancers. Further, currently employed immunosuppressive regimens offer little protection against chronic rejection and have significant toxicity. Clearly, generation of therapeutics capable of donor Ag-specific suppression is ideal, if not necessary to reduce dependence on chronic pharmacologic agents.

Immune mechanisms of allograft rejection: The diversity and robustness of the alloresponse constitute major challenges to preventing graft rejection. Both the innate and adaptive immune responses are contributory. Mechanisms of graft damage include contact-dependent $\mathrm{T}$ cell cytotoxicity, granulocyte activation by Th1 or Th2 cytokines, NK cell-mediated cytotoxicity, delayedtype hypersensitivity like reaction and allo- $\mathrm{Ab}$ and complement activation (Moine et al., 2002).

Ischemia-reperfusion injury: Ischemia-reperfusion injury refers to tissue damage resulting from the return of blood supply to tissue after a period of ischemia. This injury is Ag-independent and is responsible for initiating the events associated with rejection. Land et al. (1994) developed the "injury hypothesis" by showing that intraoperative treatment of cadaver-derived renal allografts with a free-radical scavenger reduced the incidence of acute rejection and improved long-term graft outcome (Land et al., 1994). Tissue injury up-regulates proinflammatory mediators, inducing a robust innate immune response that in turn further promotes inflammation (LaRosa et al., 2007). The innate immune response occurs prior to and independently of the adaptive immune response (Christopher et al., 2002; He et al., 2002; 2003), as RAG-deficient cardiac transplant recipients experience comparable cellular infiltration, chemokine receptor expression and pro-inflammatory cytokine expression with wild-type recipients 1 day posttransplantation (He et al., 2002).

Innate immune cells express non-rearranged pattern recognition receptors that recognize not only conserved pathogen-derived molecules, as originally appreciated (Medzhitov and Janeway, 2002) but also self-derived molecules released from damaged or stressed tissue (Mollen et al., 2006). Optimal inflammatory responses to liver damage by ischemiareperfusion injury requires signaling through toll-like receptor 4 (TLR4) expressed on hematopoietic-derived phagocytes and activated by products of necrotic cells or extracellular matrix disruption (Shen et al., 2005a; 2005b; Tsung et al., 2005a; Zhai et al., 2004). Interestingly, in humans, studies of lung transplant patients and kidney transplant recipients that are heterozygous for either of two TLR4 functional polymorphisms associated with LPS hyporesponsiveness both showed a reduced incidence of acute allograft rejection (Ducloux et al., 2005; Palmer et al., 2003). This is likely due to abundance of various redundant danger signals. Levels of the danger signal High-Mobility Group Box 1 (HMGB1) are increased following liver ischemia-reperfusion injury as early as $1 \mathrm{~h}$ following transplantation and neutralization of HMGB1 decreases markers of liver inflammation (Tsung et al., 2005b). Likewise, inhibiting signals of receptor for Advanced Glycation End products (RAGE), the receptor for HMGB1, prolongs survival of fully allogeneic cardiac allografts (Moser et al., 2007). 
Am. J. Immunol., 8 (2): 52-64, 2012

Notably, danger signals seem to persist within allografts long after transplantation, as $\mathrm{T}$ cell-deficient mice transplanted with mismatched skin or cardiac allografts that are allowed to heal for 50 days, rapidly reject their grafts upon $\mathrm{T}$ cell reconstitution (Anderson et al., 2001; Bingaman et al., 2000). If homeostatic proliferation is taken into account using a model devoid of secondary lymphoid organs but containing a normal $\mathrm{T}$ cell compartment, allografts display histological evidence of chronic rejection, but are not acutely rejected (Chalasani et al., 2004).

Innate immune response: Polymorphonuclear cells (PMN), or neutrophils, rapidly infiltrate allografts following surgery and ischemia/reperfusion injury. Neutrophils have numerous cytotoxic and proinflammatory mechanisms, including release of proinflammatory cytokines and chemoattractants and production of reactive oxygen and nitrogen species. In a rat liver model of ischemia-reperfusion injury, depletion of neutrophils abrogates tissue damage (Jaeschke et al., 1990) and neutralization of KC/CXCL1, a potent neutrophil chemoattractant, decreases PMN infiltration and prolongs graft survival (Morita et al., 2001).

NK cells are also important contributors to allograft rejection. Based on the 'missing self' hypothesis, NK cells recognize cells lacking expression of self-MHC class I molecules. NK cells are not sufficient to reject solid organ allografts, as Rag-/- or SCID mice, that lack $\mathrm{T}$ and $\mathrm{B}$ cells, fail to reject skin or heart allografts (Bingaman et al., 2000; Kitchens et al., 2006). NK cells do however contribute to tissue damage and amplify graft inflammation through release of the proinflammatory cytokines IFN- $\gamma$ and TNF- $\alpha$ and through contact-mediated cytotoxicity (Obara et al., 2005). Further, NK cell depletion in CD28-/- mice, whose T cells are unable to receive co-stimulation, prolongs fully MHC-mismatched cardiac allograft survival (Maier et al., 2001), suggesting that NK cells influence the adaptive immune response (McNerney et al., 2006).

Macrophages (MФ) are also believed to be important for rejection, although their importance may be organ or model dependent. $М \Phi$ contribute to an inflammatory response in multiple ways. They phagocytose necrotic debris, secrete pro-inflammatory cytokines, produce reactive nitrogen and oxygen species and present $\mathrm{Ag}$ to effector T cells (Wyburn et al., 2005). In rat renal allografts, $\mathrm{M} \Phi$ begin infiltrating allografts within $24 \mathrm{~h}$ following surgery and proliferate in situ (Grau et al., 1998) and in human acute renal rejection, М $\Phi$ accumulate in significant numbers (Hancock et al., 1983). Also in a rat renal transplant model, liposomal clodronate administration $1 \mathrm{~d}$ posttransplantation, which depletes the majority of $\mathrm{M} \Phi$, reduces allograft damage (Jose et al., 2003), although liposomal clodronate also depletes other subsets of monocytes and DC thus complicating interpretation of the data. The production of iNOS in particular seems important for allograft rejection, as its neutralization prolongs cardiac allograft survival in mice (Roza et al., 2000; Worrall et al., 1995).

Adaptive immune response: There are two mechanisms by which donor-reactive $\mathrm{T}$ cells recognize alloAg: the direct and the indirect pathways of allorecognition (Fig. 1) (Game and Lechler, 2002). By the direct pathway, recipient $\mathrm{T}$ cells recognize intact donor $\mathrm{MHC}$ molecules expressed on the surface of donor APC transplanted along with the allograft (i.e. donor DC, macrophages, endothelial cells) (Lombardi et al., 1989). Ischemiareperfusion injury and surgical trauma activate donor DC inducing their migration as "passenger leukocytes" to recipient secondary lymphoid organs, where they prime donor-reactive $\mathrm{T}$ cells (Anderson et al., 2001). The precursor frequency of direct pathway $\mathrm{T}$ cells is extremely high, roughly 1-10\% (Baker et al., 2001) of the $\mathrm{T}$ cell pool. This direct $\mathrm{T}$ cell alloreactivity likely results from cross-reactivity between intact allogeneic MHC molecules and self-MHC-foreign peptide complexes (Lombardi et al., 1989).

By the indirect pathway, recipient $\mathrm{T}$ cells recognize self-MHC molecules presenting donor-derived allopeptides on recipient APC (Benichou et al., 1992; Liu et al., 1996). The precursor frequency of indirect pathway $\mathrm{T}$ cells is extremely low $(1: 100,000-200,000)$ and similar to that for any other conventional/nominal Ag. It is unknown whether recipient APC mobilized into the graft acquire alloAg, then traffic to secondary lymphoid organs to prime indirect pathway $\mathrm{T}$ cells, or whether alloAg derived from the graft, either in the form of passenger leukocytes or soluble MHC molecules, enters secondary lymphoid organs where it is taken up by lymphoid-resident DC for presentation. Either way, recipient APC internalize donor Ag and process it into peptide for presentation by self-MHC to indirect pathway $\mathrm{T}$ cells.

Recently, a third "semi-direct" pathway of allorecognition has been identified in mouse models. By the semi-direct pathway, intact donor MHC molecules are acquired by recipient APC and are presented intact to direct pathway $\mathrm{T}$ cells (Herrera et al., 2004).

The semi-direct pathway is one proposed model challenging the existing paradigm that direct pathway $\mathrm{T}$ cells are primed independently of recipient APC and the indirect pathway (Fig. 2a, d). Alternatively, the 4-cell hypothesis suggests that indirect pathway $\mathrm{CD}^{+} \mathrm{T}$ helper cells stimulated by recipient APC provide unlinked bystander help to direct pathway $\mathrm{CD}^{+} \mathrm{T}$ cells stimulated by donor APC (Fig. 2b, c). Indirect $\mathrm{CD}^{+} \mathrm{T}$ cells could also provide CD40-mediated stimulation of 
Am. J. Immunol., 8 (2): 52-64, 2012

recipient APC that in turn might stimulate the direct pathway response through an unknown mechanism (Fig. 2b), or via interaction between a B cell receptor, if the recipient APC were a $\mathrm{B}$ cell, with donor MHC:alloAg on the surface of donor APC (Fig. 2c).

$\mathrm{T}$ cells are both necessary and sufficient for allograft rejection of almost all tissues. Acute graft rejection is considered $\mathrm{T}$ cell dependent, as several studies demonstrate that mice lacking T cells accept fully MHCmismatched allografts and that $\mathrm{T}$ cell reconstitution results in rejection. Due to the high precursor frequency of direct pathway $\mathrm{T}$ cells (approximately 1000 fold greater than indirect pathway $\mathrm{T}$ cells), it is assumed that the direct pathway is the more significant contributor of acute rejection (Larsen et al., 1990; Lechler and Batchelor, 1982; Talmage et al., 1976). However, as the supply of donor APC within the graft wanes over time, the contribution of the direct pathway decreases. Human studies confirm that the direct pathway response is strongest in the period immediately following transplantation. Comparatively, alloAg is shed from the graft continuously and due to epitope spreading (Ciubotariu et al., 1998), the significance of the indirect pathway increases (Valujskikh et al., 1998). As such, it is considered the main mediator of chronic rejection, which is confirmed in human studies of chronically rejected heart, kidney and lung (Ciubotariu et al., 1998; Frasca et al., 1998; Hornick et al., 2000; Lee et al., 2001; Liu et al., 1996; Reznik et al., 2001; Valujskikh et al., 1998; Vella et al., 1997).

Notably, there is evidence supporting the ability of the indirect pathway to mediate acute rejection. In human recipients of heart, kidney and liver allografts, in vitro detection of the indirect response shows strong correlation with episodes of rejection (Dalchau et al., 1992; Vella et al., 1997) and immunization of animals with peptide derived from allogeneic MHC (thus presented through the indirect pathway) causes allograft rejection (Fangmann et al., 1992a; 1992b). Finally, using a cardiac allograft transplant model in mice, Auchincloss et al. (1993) showed that the indirect pathway is sufficient to elicit graft rejection in the absence of direct allorecognition (Auchincloss et al., 1993). The relative contributions of the indirect and direct pathway were evaluated in skin, cornea and retina and results reveal that the importance of each pathway appears to be organ dependent (Illigens et al., 2002). As expected, skin allografts have a pronounced direct pathway response, likely attributable to their high passenger APC load. Comparatively, cornea had a more potent indirect pathway response, again not surprising given its low level of MHC molecule expression. Such studies are yet to be performed in heart transplantation, although given the low number of passenger leukocytes, one might expect increased importance of the indirect response.
$\mathrm{T}$ cells contribute to allograft rejection by various mechanisms. Contact mediated cytotoxicity and release of pro-inflammatory cytokines are both potent mechanisms of allograft damage. Typically, the allograft response is Th1, IFN- $\gamma$ mediated, however both Th1 and Th2 effector responses can cause allograft rejection (Moine et al., 2002). Further, T cells stimulate other immune cells to cause damage. B cell function and the alloAb response depends on indirect pathway $\mathrm{CD}^{+}{ }^{+} \mathrm{T}$ cell help because B cells recognizing Ag via $\mathrm{B}$ cell receptors internalize, process and present antigenic peptides loaded in selfMHC to $\mathrm{T}$ cells, that in turn, provide the necessary help for B cell effector function and Ab class switching (Steele et al., 1996; Terasaki, 2003). Indirect pathway $\mathrm{T}$ cells could also stimulate recipient $M \Phi$ or DC within the graft to release proinflammatory molecules in a DTH-like response. This previously has been associated with chronic rejection, however it is possible that the cytotoxic molecules released by $\mathrm{M} \Phi / \mathrm{DC}$ could contribute to acute rejection, particularly since one stimulated M $\Phi / D C$ could damage numerous surrounding donor cells simultaneously, while one $\mathrm{CD}^{+}$cytotoxic $\mathrm{T}$ cell targets only one donor cell at a time.

Cellular therapies in solid organ transplantation: The concept of utilizing cellular therapies to induce allograft tolerance has its roots in the earliest studies of transplantation. Billingham et al. (1953) showed that infusion of donor allogeneic cells into newborn mice resulted in acceptance of skin allografts in the absence of immunosuppression (Billingham et al., 1953). More recently, Sayegh et al. (1993) demonstrated that intrathymic injection of donor allopeptides prolongs subsequent allografts of the same MHC, further indicating that exposure of recipients to donor $\mathrm{Ag}$ prior to transplantation has a tolerizing effect. Currently, there are three types of cellular therapies proposed for use in transplantation. Donor-Specific Transfusion (DST) refers to the transfer of donor splenocytes in mice, or peripheral blood mononuclear cells in humans, directly from donor to recipient with little manipulation. DST has been employed in the clinic for decades and in some cases successfully decreased the anti-donor immune response and prolonged allograft survival. However, prevention of acute rejection was not universally achieved and DST was associated with risk of recipient sensitization, thus the advent of pharmacologic immunosuppressive agents replaced DST as the main prophylactic for transplant recipients. Ironically, the negative side effects of pharmacologic immunosuppression coupled with the new goal of achieving operational tolerance, defined as long-term freedom from all immunosuppression with normal graft function, has resulted in a renewed interest in cellular therapies. 
Am. J. Immunol., 8 (2): 52-64, 2012

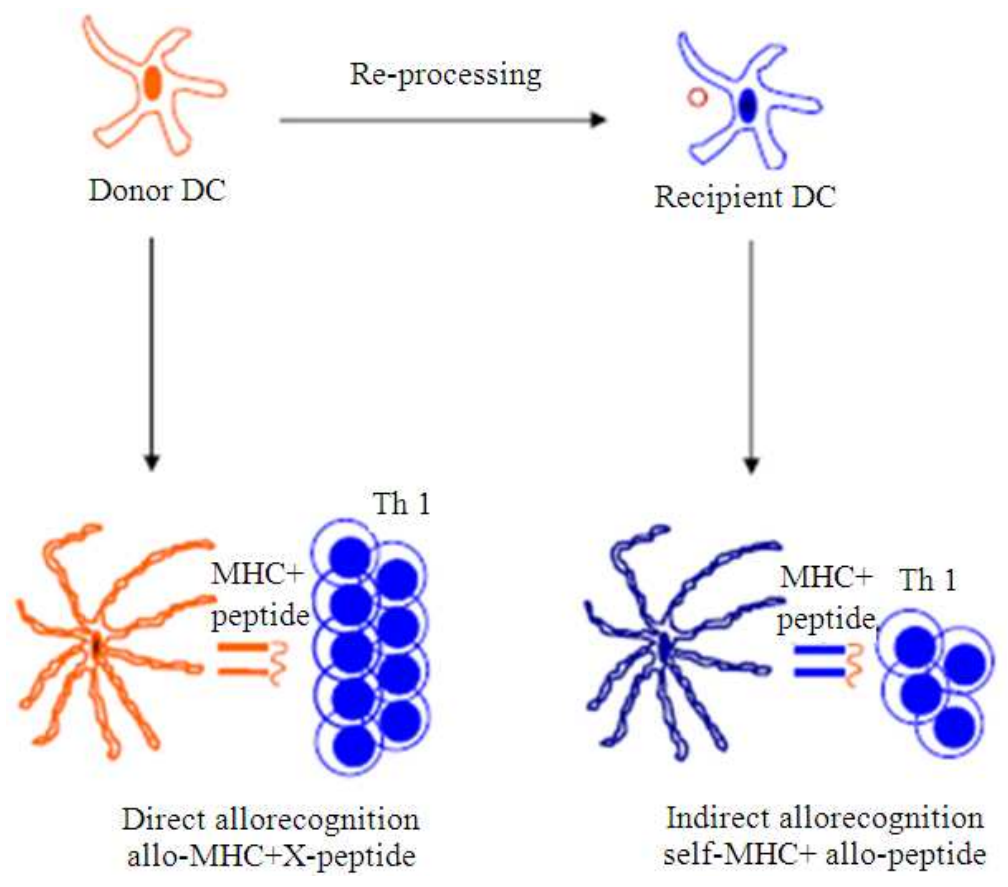

Fig. 1: Pathways of allorecognition. In the direct pathway, donor DC directly interact with anti-donor T cells. In this case, T cells recognize alloMHC: peptide complexes on the surface of donor DC. In the indirect pathway, recipient DC re-process donor alloAg derived from donor APC into allopeptide for presentation by self-MHC to anti-donor T cells.

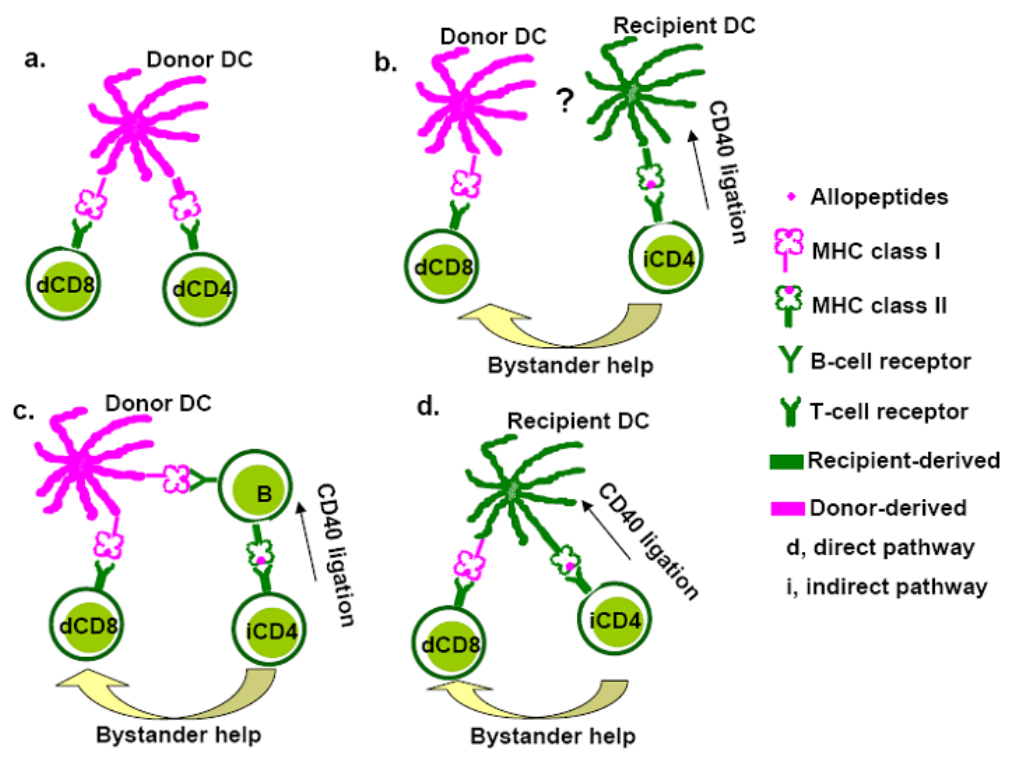

Fig. 2: Models of direct pathway $\mathrm{CD}^{+} \mathrm{T}$ cell priming. (a) Direct pathway $\mathrm{T}$ cells are primed by donor APC independently of recipient APC or indirect T cells. (b) Indirect pathway $\mathrm{CD}^{+}$helper $\mathrm{T}$ cells stimulated by recipient APC provide unlinked bystander help to direct pathway $\mathrm{CD}^{+} \mathrm{T}$ cells stimulated by donor APC. (c, d) Indirect $\mathrm{CD}^{+} \mathrm{T}$ cells provide $\mathrm{CD} 40$-mediated stimulation of recipient APC that in turn might stimulate the direct pathway response via (c) interaction between a B cell receptor, if the recipient APC were a B cell, or (d) a recipient DC with donor MHC:alloAg on its surface. 
Advancements in understanding peripheral tolerance mechanisms has led to development of newer cellular therapies including donor apoptotic cell therapy and tolerogenic DC therapies.

DST in transplantation of solid organ allografts: Quezada et al. (2003) showed that DST significantly prolongs skin allograft survival through peripheral deletion of indirect pathway $\mathrm{CD}^{+} \mathrm{T}$ cells and increased numbers of regulatory $\mathrm{T}$ cells (Treg). Brouard and Soulillou and colleagues demonstrated that infusion of splenocytes without additional immunosuppression leads to long-term survival of cardiac allografts through expansion of Treg and that transfer of long-term survivor splenic $\mathrm{T}$ cells to new allograft recipients transfers long-term allograft survival in an Ag-specific manner (Lair et al., 2007). Importantly, in the Quezada study, the injected living donor splenocytes did not directly interact with $\mathrm{CD}^{+} \mathrm{T}$ cells (Quezada et al., 2003). This finding suggests that living splenocytes upon i.v. injection in some way transfer alloAg to recipient APC for indirect presentation rather directly interacting with direct pathway $\mathrm{T}$ cells.

Apoptotic cell therapy in transplantation of solid organ allografts: Our group has investigated apoptotic cell therapy in allograft survival and demonstrated in mice that i.v. administration of donor-derived UV-Birradiated apoptotic splenocytes $7 \mathrm{~d}$ prior to transplantation significantly prolongs survival of heart allografts in the absence of immunosuppression (Wang et al., 2006). Moreover, combination of donor apoptotic splenocytes with suboptimal blockade of the CD40CD154 pathway with a single dose of anti-CD154 Ab results in long-term survival of cardiac transplants for more than $100 \mathrm{~d}$ (Wang et al., 2006). The therapeutic effect of donor apoptotic cells was donor-specific and required interaction of the apoptotic cells with recipient DC in secondary lymphoid organs. It also depended on the physical properties of the donor leukocytes, since administration of donor necrotic cells did not affect graft survival (Wang et al., 2006). We further demonstrated that i.v. administered donor-apoptotic cells are rapidly phagocytosed by recipient splenic DC, which present apoptotic cell-derived allopeptides in self-MHC to indirect pathway $\mathrm{T}$ cells (Wang et al., 2006). Interestingly, splenic transgenic $\mathrm{CD}^{+} \mathrm{T}$ cells specific for indirect pathway $\mathrm{Ag}$ proliferated in response to injection of $\mathrm{BALB} / \mathrm{c}$ apoptotic splenocytes, but did not upregulate expression of the $\mathrm{T}$ cell activation markers CD25, CD44, CD69 and CD152 and secreted lower amounts of IL-2 and IFN- $\chi$ upon ex vivo re-stimulation when compared to controls. Importantly, the defective activation of anti-donor indirect pathway $\mathrm{CD}^{+} \mathrm{T}$ cells resulted in their peripheral deletion, as their numbers decreased significantly in spleen, LN, blood and peripheral tissues, $14 \mathrm{~d}$ after administration of apoptotic cells.

Besides inducing peripheral deletion of donorreactive $\mathrm{T}$ cells, administration of donor apoptotic splenocytes in combination with suboptimal CD40CD154 blockade promotes differentiation/expansion of donor-specific CD4 ${ }^{+}$Treg (Wang et al., 2006), reduces significantly the level of circulating alloAb in cardiac allograft recipients (Wang et al., 2006) and in aortic allograft transplantation, a model of chronic rejection, results in significant inhibition of the histopathological features of chronic vascular arteriopathy, the classic feature of chronic rejection (Wang et al., 2009).

Dendritic cell-based therapies in transplantation of solid organ allografts: DC are a heterogeneous population of hematopoietic-derived APC that orchestrate the adaptive immune response to self- and foreign-Ag. DC are defined by surface expression of MHC class-II molecules, expression of the integrin and complement receptor CD11c (in mice) and their unique ability to stimulate naïve $\mathrm{T}$ cells (Banchereau et al., 2000). DC respond to both endogenous and exogenous danger signals such as pathogen-associated molecular patterns on microorganisms, products secreted by activated $\mathrm{M} \Phi$ and parenchymal cells and stimulatory signals from activated T cells (Banchereau et al., 2000). Since they are the only APC capable of priming naïve $\mathrm{T}$ cells, they serve as a crucial link between innate and adaptive immunity (Banchereau et al., 2000; Banchereau and Steinman, 1998).

In the periphery, DC exist in 3 different stages of activation/maturation: immature, semi-mature or quiescent and mature or activated (Fig. 3). In the steady-state, quiescent DC are highly phagocytic and express low surface levels of MHC : peptide complexes and the co-stimulatory molecules CD80 and CD86 (Banchereau et al., 2000; Banchereau and Steinman, 1998; Cella et al., 1997). DC mature upon exposure to pro-inflammatory stimuli. During maturation, DC decrease phagocytic ability and increase their surface expression of MHC class-I and -II: peptide complexes, CD40, CD80 and CD86 (Cella et al., 1997). The MHC: peptide complexes presented by $\mathrm{DC}$ bind the $\mathrm{T}$ cell receptor (TCR) (signal 1), while CD80 and CD86 bind CD28 (signal 2) on the surface of the $\mathrm{T}$ cell. This induces secretion of IL-2, which is a potent agonist for $\mathrm{T}$ cell activation/proliferation (Lenschow et al., 1996). Additionally, the interaction between CD40 on the DC and CD40Ligand (CD40L or CD154) on the $\mathrm{T}$ cell surface further enhances $\mathrm{DC}$ and $\mathrm{T}$ cell stimulation (Grewal and Flavell, 1998). 
Am. J. Immunol., 8 (2): 52-64, 2012

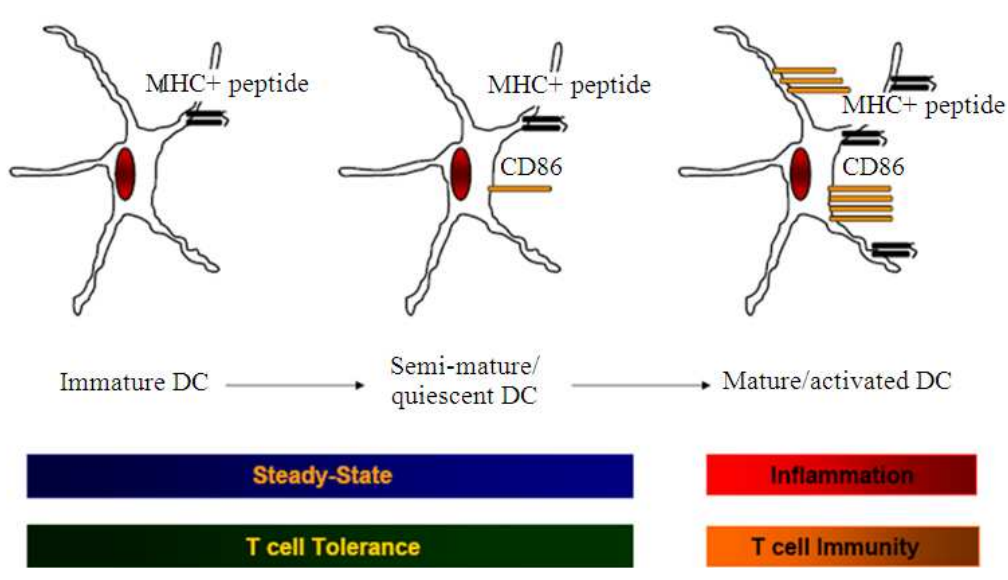

Fig 3: Stages of DC maturation. DC can exist as either immature (express low levels of MHC: peptide complex without co-stimulatory molecules CD80 or CD86), semi-mature or quiescent (express low levels of MHC:peptide complex along with low levels of co-stimulatory molecules), or mature or activated (express high levels of MHC:peptide complex and high levels of co-stimulatory molecules).

Mature DC secrete soluble mediators (signal 3) which help direct the immune response, such as IL-12p70, which polarizes $\mathrm{T}$ cells toward a Th1 response (Banchereau et al., 2000; Banchereau and Steinman, 1998; Cella et al., 1997).

DC as inducers of $\mathbf{T}$ cell tolerance: Although most $\mathrm{T}$ cells recognizing self-peptides with high affinity are eliminated centrally in the thymus through negative selection (Brocker et al., 1997), a percentage of selfreactive $\mathrm{T}$ cells escape thymic deletion and access the periphery. An efficient mechanism in the periphery is therefore necessary to prevent activation of self-reactive $\mathrm{T}$ cells and avoid autoimmunity.

Quiescent DC expressing MHC: Peptide complexes (signal 1) with low levels of co-stimulatory signals (signal 2) provide sub-threshold stimulation to autoreactive $\mathrm{T}$ cells, resulting in defective $\mathrm{T}$ cell activation (Schwartz, 1990; Steinman et al., 2003; Steinman and Nussenzweig, 2002). Incomplete $T$ cell activation results in poor cellular proliferation followed by deletion, anergy and likely differentiation/expansion of Treg cells, all mechanisms leading to $\mathrm{T}$ cell hyporesponsiveness or tolerance (Steinman et al., 2003; Steinman and Nussenzweig, 2002).

DC therapies in transplantation of solid organ allografts: The ability of DC to tolerize $\mathrm{T}$ cells in an Ag-specific manner, coupled with the ability to propagate large numbers of DC in vitro, has heralded the use of tolerogenic/immunosuppressive DC as therapeutics for transplantation and autoimmunity. Tolerogenic DC are in an immature or quiescent state, in that they express low levels of MHC: peptide complexes with or without low amounts of costimulatory molecules (Fig. 3) and are impaired in their ability to produce the Th1-driving cytokine IL-12p70. A number of methods, including culture-conditioning with different cytokines or growth factors, treatment with various pharmacologic agents and genetic engineering (Table 1) (Morelli and Thomson, 2007) have been developed to increase DC tolerizing potential and/or render tolerogenic DC resistant to maturation, to combat the risk of in vivo maturation of the administered DC and thus patient sensitization.

These pharmacologic or genetic manipulations affect DC differentiation and function by various mechanisms (Morelli and Thomson, 2007). Some tolerogenic DC express high levels of co-inhibitory molecules such as PD-L1 on their surface, or have a lower net ratio of co-stimulatory to co-inhibitory molecule expression (i.e., CD86 : PD-L1). Secretion of inhibitory cytokines/mediators also is variable, as some tolerogenic DC release IL-10, which has been shown to inhibit $\mathrm{T}$ cell expansion ( $\mathrm{Li}$ et al., 2005). Further, tolerogenic DC can induce activation-induced cell death through FasL expression or induce Treg through IDO expression (Bohana-Kashtan and Civin, 2004; Mellor et al., 2004). A number of different types of tolerogenic DC, many with different phenotypic and functional characteristics have been studied in mouse models of heart transplantation using a heterotopic cardiac allograft model. These tolerogenic DC therapies prolong allograft survival with a Mean Survival Time (MST) between 20 and 50 days (Emmer et al., 2006; Lan et al., 2006; O'Connell et al., 2002; Tang et al., 2006; Turnquist et al., 2007). Typically, an increased percentage of Treg is observed along with decreased $\mathrm{T}$ cell effector responses. 
Am. J. Immunol., 8 (2): 52-64, 2012

Table 1: Methods of generating tolerogenic DC in vitro

\begin{tabular}{lll}
\hline Cytokines, growth factors & Pharmacologic mediators & Genetic engineering \\
\hline$\downarrow$ GM-CSF & Immunosuppresstive or anti-inflammatory drugs & Recombinant viral vectors or naked DNA: \\
$\uparrow$ IL-10 & Cyclosporine & CD95L (FasL) \\
$\uparrow$ TGF $\beta 1$ & Rapamycin & CTLA4-Ig \\
$\uparrow$ VEGF & Tacrolimus & IL-10 \\
& Deoxyspergualin & TGF 31 \\
& Mycophenolate mofetil & IDO \\
& Sanglifehrin A & Soluble TNFR \\
& Corticosteroids & CCR7 \\
& A spirin & Dominant-negative $\mathrm{I}_{\mathrm{K}} \mathrm{B}$ \\
& $1 \alpha, 25$-dihydroxyvitamin $\mathrm{D}_{3}$ & Kinase \\
& N-acety-L-cysteine & ODNs; \\
& Cyclic AMP inducers & NF-K-specific decoy \\
& Glucosamine & RAN interference: \\
& Cobalt protoporphyrin & RELB \\
& ILT receptor ligands & IL-10 \\
\hline
\end{tabular}

Although these different tolerogenic DC vary phenotypically in vitro, the similar effect on allograft survival and anti-donor $\mathrm{T}$ cell responses suggests similar mechanism of action in vivo.

It has been assumed that therapeutic tolerogenic DC, once administered i.v. to prospective graft recipients, interact directly with anti-donor $\mathrm{T}$ cells. Given the preponderance of the direct pathway in acute allograft rejection, it has further been assumed that the ability to down-modulate the direct pathway response makes DC therapies superior to alternative cellular therapies (DST and apoptotic cell therapy) in transplantation.

Our group has investigated the mechanisms by which DC therapy functions in vivo to prolong cardiac allograft survival in a mouse model. We demonstrated that donor-derived DC rapidly die once transfused into the prospective graft recipient and that apoptotic cell fragments derived from the injected therapeutic DC are taken up by the recipient's DC and processed into donor alloAg for presentation via recipient MHC molecules to indirect pathway $\mathrm{CD}^{+} \mathrm{T}$ cells (Divito et al., 2010). If the recipient DC are quiescent, then this process induces defective activation of indirect pathway $\mathrm{CD}^{+} \mathrm{T}$ cells with preferential survival of Treg (Divito et al., 2010). We have further shown that recipient DC are necessary for DC therapy prolongation of allograft survival using CD11c-DTR bone marrow chimeric mice to selectively deplete recipient but not donor DC (Wang et al., 2012). Finally, we showed that apoptotic cell therapy, DST and DC therapy all act via the same mechanism of action, that is, they serve as a source of donor alloAg for recipient DC, rather than through direct interaction with anti-donor T cells (Divito et al., 2010).

A brief statement on $T$ cell-based therapies in transplantation: In addition to the above named cellular therapies, the possibility of employing regulatory and/or anergic $\mathrm{T}$ cells generated and expanded in vitro, ex vivo, or even in vivo, to modulate the anti-graft response has received great attention over the past decade. Various methodologies of generating regulatory and/or anergic $\mathrm{T}$ cells have been studied in multiple animal models of organ transplantation with initial promising results (reviewed by (McMurchy et al., 2011)) and Tregs generated in vitro have been utilized in clinical trials for graft-versus-host disease in stem cell transplantation, demonstrating its clinical feasibility (Brunstein et al., 2011; Ianni et al., 2011; Trzonkowski et al., 2009). Given the expanse of literature on $\mathrm{T}$ cell based-therapies in transplantation, as well as in autoimmunity and graft-versus-host-disease, they will not be discussed further here, except to say that $\mathrm{T}$ cell-based therapies are a major area of research in the transplantation community and warrant further research.

\section{CONCLUSION}

Despite the promising results of cell-based therapies in animal models, it is important to acknowledge caveats to current research and roadblocks to clinical translation. First, most research on cellular therapies in transplantation has been conducted using young inbred mice maintained in clean or nearly pathogen-free conditions, which therefore may possess low numbers of memory $\mathrm{T}$ cells compared to outbred animals. Comparatively, transplant rejection in humans is mediated by both naïve and memory $\mathrm{T}$ cells and as such, the ability of cellular therapies to tolerize not only recipient DC-naive $\mathrm{T}$ cell interaction, but also other non-professional recipient APC capable of activating anti-donor memory $\mathrm{T}$ cells, will likely be critical for successful therapy.

Second, safety is a major area of concern. What if a preparation of cellular therapeutic contained traces of effector cells? Or if a batch of the tolerizing agent was ineffective? And if administration of a cellular therapy 
had a deleterious effect, could the adoptively transferred cell be eliminated from the patient? In reality, it is likely that cellular therapeutics would never be instituted in the clinic as a single therapy, but rather in combination with additional pharmacologic immunosuppression. This may help alleviate some of the risks associated with cellular products. Further, clinical experience with cellular therapeutics is being gained from the fields of stem cell transplantation and cancer.

Solid organ transplantation remains a clinical challenge despite its increasing prevalence. Many questions remain in regards to the immunopathogenesis of allograft rejection and whether cellular therapies will ultimately have a role in preventing rejection. Regardless, optimization and application of cellular therapies represents an active area of research in transplant immunology and still holds promise for clinical use.

\section{REFERENCES}

Afzali, B., R.I. Lechler and M.P. Hernandez-Fuentes, 2007. Allorecognition and the alloresponse: clinical implications. Tissue Antigens, 69: 545556. PMID: 17498264

Anderson, C.C., J.M. Carroll, S. Gallucci, J.P. Ridge and A.W. Cheever, 2001. Testing time-, ignoranceand danger-based models of tolerance. J. Immunol., 166: 3663-3671. PMID: 11238605

Auchincloss, H., J.R. Lee, S. Shea, J.S. Markowitz and M.J. Grusby, 1993. The role of "indirect" recognition in initiating rejection of skin grafts from major histocompatibility complex class IIdeficient mice. Proc. Natl. Acad. Sci., 90: 33733377. PMID: 8475083

Baker, R.J., M.P. Hernandez-Fuentes, P.A. Brookes, A.N. Chaudhry and R.I. Lechler, 2001. The role of the allograft in the induction of donor-specific $t$ cell hyporesponsiveness. Transplantation, 72: 480-485.

Banchereau, J. and R.M. Steinman, 1998. Dendritic cells and the control of immunity. Nature, 392: 245-252. PMID: 9521319

Banchereau, J., F. Briere, C. Caux, J. Davoust and S. Lebecque et al., 2000. Immunobiology of dendritic cells. Annu. Rev. Immunol., 18: 767-811. PMID: 10837075

Benichou, G., P.A. Takizawa, C.A. Olson, M. McMillan and E.E. Sercarz, 1992. Donor Major Histocompatibility Complex (MHC) peptides are presented by recipient $\mathrm{MHC}$ molecules during graft rejection. J. Exp. Med., 175: 305-308. PMID: 1730925
Billingham, R.E., L. Brent and P.B. Medawar, 1953. Actively acquired tolerance of foreign cells. Nature, 172: 603-606. PMID: 13099277

Bingaman, A.W., J. Ha, S.Y. Waitze, M.M. Durham and H.R. Cho et al., 2000. Vigorous allograft rejection in the absence of danger. J. Immunol., 164: 3065-3071. PMID: 10706695

Bohana-Kashtan, O. and C.I. Civin, 2004. Fas ligand as a tool for immunosuppression and generation of immune tolerance. Stem Cells, 22: 908-924. PMID: 15536183

Brocker, T., M. Riedinger and K. Karjalainen, 1997. Targeted expression of Major Histocompatibility Complex (MHC) class II molecules demonstrates that dendritic cells can induce negative but not positive selection of thymocytes in vivo. J. Exp. Med., 185: 541-550. PMID: 9053454

Brunstein, C.G., J.S. Miller, Q. Cao, D.H. McKenna and K. L. Hippen et al., 2011. Infusion of ex vivo expanded $\mathrm{T}$ regulatory cells in adults transplanted with umbilical cord blood: Safety profile and detection kinetics. Blood, 117: 1061-1070.

Cella, M., F. Sallusto and A. Lanzavecchia, 1997. Origin, maturation and antigen presenting function of dendritic cells. Curr. Opin. Immunol., 9: 10-16. PMID: 9039784

Chalasani, G., Q. Li, B.T. Konieczny, L. Smith-Diggs and B. Wrobel et al., 2004. The allograft defines the type of rejection (acute versus chronic) in the face of an established effector immune response. J. Immunol., 172: 7813-7820. PMID: 15187165

Christopher, K., T.F. Mueller, C. Ma, Y. Liang and D.L. Perkins, 2002. Analysis of the innate and adaptive phases of allograft rejection by cluster analysis of transcriptional profiles. J. Immunol., 169: 522-530. PMID: 12077284

Ciubotariu, R., Z. Liu, A.I. Colovai, E. Ho and S. Itescu et al., 1998. Persistent allopeptide reactivity and epitope spreading in chronic rejection of organ allografts. J. Clin. Invest., 101: 398-405. DOI: 10.1172/JCI1117

Dalchau, R., J. Fangmann and J.W. Fabre, 1992. Allorecognition of isolated, denatured chains of class I and class II major histocompatibility complex molecules. Evidence for an important role for indirect allorecognition in transplantation. Eur. J. Immunol. 22: 669-677. PMID: 1547813

Divito, S.J., Z. Wang, W.J. Shufesky, Q. Liu and O.A. Tkacheva et al., 2010. Endogenous dendritic cells mediate the effects of intravenously injected therapeutic immunosuppressive dendritic cells in transplantation. Blood, 116: 2694-2705. DOI: 10.1182/blood-2009-10-251058 
Ducloux, D., M. Deschamps, M. Yannaraki, C. Ferrand and J. Bamoulid et al., 2005. Relevance of Tolllike receptor-4 polymorphisms in renal transplantation. Kidney Int., 67: 2454-2461. PMID: 15882292

Emmer, P.M., J. van der Vlag, G.J. Adema and L.B. Hilbrands, 2006. Dendritic cells activated by lipopolysaccharide after dexamethasone treatment induce donor-specific allograft hyporesponsiveness. Transplantation, 81: 14511459. DOI: 10.1097/01.tp.0000208801.51222.bd

Fangmann, J., R. Dalchau and J.W. Fabre, 1992a. Rejection of skin allografts by indirect allorecognition of donor class I major histocompatibility complex peptides. J. Exp. Med., 175: 1521-1529. PMID: 1588278

Fangmann, J., R. Dalchau, G.J. Sawyer, C.A. Priestley and J.W. Fabre, 1992b. T cell recognition of donor major histocompatibility complex class Ipeptides during allograft rejection. Eur. J. Immunol., 22: 1525-1530. DOI: 10.1002/eji.1830220627

Frasca, L., A. Amendola, P. Hornick, P. Brookes and G. Aichinger et al., 1998. Role of donor and recipient antigen-presenting cells in priming and maintaining $\mathrm{T}$ cells with indirect allospecificity. Transplantation, 66: 1238-1243. PMID: 9825823

Gallon, L.G., J.R. Leventhal and D.B. Kaufman, 2002. Pretransplant evaluation of renal transplant candidates. Semin. Nephrol., 22: 515-525. PMID: 12430096

Game, D.S. and R.I. Lechler, 2002. Pathways of allorecognition: Implications for transplantation tolerance. Transpl. Immunol., 10: 101-108. PMID: 12216939

Grau, V., B. Herbst and B. Steiniger, 1998. Dynamics of monocytes/macrophages and $\mathrm{T}$ lymphocytes in acutely rejecting rat renal allografts. Cell Tissue Res., 291: 117-126. PMID: 9394049

Grewal, I.S. and R.A. Flavell, 1998. CD40 and CD154 in cell-mediated immunity. Annu. Rev. Immunol., 16: 111-135. PMID: 9597126

Hancock, W.W., N.M. Thomson and R.C. Atkins, 1983. Composition of interstitial cellular infiltrate identified by monoclonal antibodies in renal biopsies of rejecting human renal allografts. Transplantation, 35: 458-463. PMID: 6342225

He, H., J.R. Stone and D.L. Perkins, 2002. Analysis of robust innate immune response after transplantation in the absence of adaptive immunity. Transplantation, 73: 853-861. PMID: 11923683
He, H., J.R. Stone and D.L. Perkins, 2003. Analysis of differential immune responses induced by innate and adaptive immunity following transplantation. Immunology, 109: 185-196. DOI: 10.1046/j.13652567.2003.01641.x

Herrera, O.B., D. Golshayan, R. Tibbott, F.S. Ochoa and M.J. James et al., 2004. A novel pathway of alloantigen presentation by dendritic cells. J. Immunol., 173: 4828-4837.

Hornick, P.I., P.D. Mason, R.J. Baker, M. HernandezFuentes and L. Frasca et al., 2000. Significant frequencies of $\mathrm{T}$ cells with indirect anti-donor specificity in heart graft recipients with chronic rejection. Circulation, 101: 2405-2410. DOI: 10.1161/01.CIR.101.20.2405

Ianni, M.D., F. Falzetti, A. Carotti, A. Terenzi, F. Castellino et al., 2011. Tregs prevent GVHD and promote immune reconstitution in HLAhaploidentical transplantation. Blood, 117: 39213928.

Ibrahim S., D.V. Dawson and F. Sanfilippo, 1995. Predominant infiltration of rejecting human renal allografts with $\mathrm{T}$ cells expressing CD8 and CD45RO. Transplantation, 59: 724-728. PMID: 7886800

Illigens, B.M., A. Yamada, E.V. Fedoseyeva, N. Anosova and F. Boisgerault et al., 2002. The relative contribution of direct and indirect antigen recognition pathways to the alloresponse and graft rejection depends upon the nature of the transplant. Hum. Immunol., 63: 912-925. PMID: 12368044

Jaeschke, H., A. Farhood and C.W. Smith, 1990. Neutrophils contribute to ischemia/reperfusion injury in rat liver in vivo. Faseb J., 4: 3355-3359.

Jose, M.D., Y. Ikezumi, N. van Rooijen, R.C. Atkins and S.J. Chadban, 2003. Macrophages act as effectors of tissue damage in acute renal allograft rejection. Transplantation, 76: 1015-1022. PMID: 14557746

Kitchens, W.H., S. Uehara, C.M. Chase, R.B. Colvin and P.S. Russell, 2006. The changing role of natural killer cells in solid organ rejection and tolerance. Transplantation, 81: 811-817. PMID: 16570001

Lair, D., N. Degauque, P. Miqueu, V. Jovanovic, M. Guillet and E. Meriea, et al., 2007. Functional compartmentalization following induction of longterm graft survival with pregraft donor-specific transfusion. Am. J. Transplant., 7: 538-549. PMID: 17217443 
Am. J. Immunol., 8 (2): 52-64, 2012

Lan, Y.Y., Z. Wang, G. Raimondi, W. Wu and B.L. Colvin et al., 2006. Alternatively activated" dendritic cells preferentially secrete IL-10, expand Foxp3+CD4+ T cells and induce long-term organ allograft survival in combination with CTLA4-Ig. J. Immunol., 177: 5868-5877. PMID: 17056511

Land, W., H. Schneeberger, S. Schleibner, W.D. Illner and D. Abendroth, 1994. The beneficial effect of human recombinant superoxide dismutase on acute and chronic rejection events in recipients of cadaveric renal transplants. Transplantation, 57: 211-217. PMID: 8310510

LaRosa, D.F., A.H. Rahman and L.A. Turka, 2007. The innate immune system in allograft rejection and tolerance. J. Immunol., 178: 7503-7509. PMID: 17548582

Larsen, C.P., J.M. Austyn and P.J. Morris, 1990. The role of graft-derived dendritic leukocytes in the rejection of vascularized organ allografts. Recent findings on the migration and function of dendritic leukocytes after transplantation. Ann. Surg., 212: 308-15; discussion 316-317. PMID: 2204317

Lechler, R.I. and J.R. Batchelor, 1982. Restoration of immunogenicity to passenger cell-depleted kidney allografts by the addition of donor strain dendritic cells. J. Exp. Med., 155: 31-41.

Lee, R.S., K. Yamada, S.L. Houser, K.L. Womer and M.E. Maloney et al., 2001. Indirect allorecognition promotes the development of cardiac allograft vasculopathy. Transplant. Proc., 33: 308-310. PMID: 11266832

Lenschow, D.J., T.L. Walunas and J.A. Bluestone, 1996. CD28/B7 system of $\mathrm{T}$ cell costimulation. Annu. Rev. Immunol., 14: 233-258. PMID: 8717514

Li, G., Y.J. Kim and H.E. Broxmeyer, 2005. Macrophage colony-stimulating factor drives cord blood monocyte differentiation into IL-10 (high) IL-12absent dendritic cells with tolerogenic potential. J. Immunol., 174: 4706-4717. PMID: 15814695

Liu, Z., A.I. Colovai, S. Tugulea, E.F. Reed and P.E. Fisher et al., 1996. Indirect recognition of donor HLA-DR peptides in organ allograft rejection. J. Clin. Invest., 98: 1150-1157. DOI: 10.1172/JCI118898

Lombardi, G., S. Sidhu, J.R. Batchelor and R.I. Lechler, 1989. Allorecognition of DR1 by T cells from a DR4/DRw13 responder mimics self-restricted recognition of endogenous peptides. Proc. Natl. Acad. Sci. USA., 86: 4190-4194.
Magee, C.C., 2006. Transplantation across previously incompatible immunological barriers. Transpl. Int., 19: 87-97. PMID: 16441356

Maier, S., C. Tertilt, N. Chambron, K. Gerauer and N. Huser et al., 2001. Inhibition of natural killer cells results in acceptance of cardiac allografts in CD28/- mice. Nat. Med., 7: 557-562. PMID: 11329056

McMurchy, A. N., A. Bushell, M. K. Levings and K. J. Wood, 2011. Moving to tolerance: clinical application of T regulatory cells. Semin. Immunol., 23: 304-313. PMID: 21620722

McNerney, M.E., K.M. Lee, P. Zhou, L. Molinero and M. Mashayekhi et al., 2006. Role of natural killer cell subsets in cardiac allograft rejection. Am. J. Transplant., 6: 505-513. PMID: 16468959

Medzhitov, R. and C.A. Janeway, 2002. Decoding the patterns of self and nonself by the innate immune system. Science, 296: 298-300. DOI: 10.1126/science. 1068883

Mellor, A.L., P. Chandler, B. Baban, A.M. Hansen and B. Marshall et al., 2004. Specific subsets of murine dendritic cells acquire potent $\mathrm{T}$ cell regulatory functions following CTLA4-mediated induction of indoleamine 2, 3 dioxygenase. Int. Immunol., 16: 1391-1401. PMID: 15351783

Moine, A.L., M. Goldman and D. Abramowicz, 2002. Multiple pathways to allograft rejection. Transplantation, 73: 1373-1381. PMID: 12023610

Mollen, K.P., R.J. Anand, A. Tsung, J.M. Prince and R.M. Levy, 2006. Emerging paradigm: Toll-like receptor 4-sentinel for the detection of tissue damage. Shock, 26: 430-437. DOI: 10.1097/01.shk.0000228797.41044.08

Morelli, A.E. and A.W. Thomson, 2007. Tolerogenic dendritic cells and the quest for transplant tolerance. Nat. Rev. Immunol., 7: 610-621. DOI: $10.1038 /$ nri2132

Morita, K., M. Miura, D.R. Paolone, T.M. Engeman and A. Kapoor et al., 2001. Early chemokine cascades in murine cardiac grafts regulate $\mathrm{T}$ cell recruitment and progression of acute allograft rejection. J. Immunol., 167: 2979-2984.

Moser, B., M.J. Szabolcs, H.J. Ankersmit, Y. Lu and W. Qu et al., 2007. Blockade of RAGE suppresses alloimmune reactions in vitro and delays allograft rejection in murine heart transplantation. Am. J. Transplant., 7: 293-302. PMID: 17241110

O'Connell, P.J., W. Li, Z. Wang, S.M. Specht and A.J. Logar, 2002. Immature and mature CD8alpha+ dendritic cells prolong the survival of vascularized heart allografts. J. Immunol., 168: 143-54. PMID: 11751957 
Obara, H., K. Nagasaki, C.L. Hsieh, Y. Ogura and C.O. Esquivel et al., 2005. IFN-gamma, produced by NK cells that infiltrate liver allografts early after transplantation, links the innate and adaptive immune responses. Am. J. Transplant., 5: 20942103. PMID: 16095488

Palmer, S.M., L.H. Burch, R.D. Davis, W.F. Herczyk and D.N. Howell et al., 2003. The role of innate immunity in acute allograft rejection after lung transplantation. Am. J. Respir. Crit. Care Med., 168: 628-632. PMID: 12773319

Pascual, M., T. Theruvath, T. Kawai, N. Tolkoff-Rubin and A.B. Cosimi, 2002. Strategies to improve longterm outcomes after renal transplantation. N. Engl. J. Med., 346: 580-590.

Quezada, S.A., B. Fuller, L.Z. Jarvinen, M. Gonzalez and B.R. Blazar et al., 2003. Mechanisms of donorspecific transfusion tolerance: Preemptive induction of clonal T-cell exhaustion via indirect presentation. Blood, 102: 1920-1926. PMID: 12750162

Reznik, S.I., A. Jaramillo, K.S. SivaSai, K.L. Womer and M.H. Sayegh et al., 2001. Indirect allorecognition of mismatched donor HLA class II peptides in lung transplant recipients with bronchiolitis obliterans syndrome. Am. J. Transplant., 1: 228-235. PMID: 12102256

Roza, A.M., M. Cooper, G. Pieper, G. Hilton and K. Dembny et al., 2000. NOX 100, a nitric oxide scavenger, enhances cardiac allograft survival and promotes long-term graft acceptance. Transplantation, 69: 227-231. PMID: 10670631

Sayegh, M.H. and C.B. Carpenter, 2004. Transplantation 50 years later--progress, challenges and promises. N. Engl. J. Med., 351: 2761-6. PMID: 15616214

Sayegh, M.H., N. Perico, O. Imberti, W.W. Hancock and C.B. Carpenter, 1993. Thymic recognition of class II major histocompatibility complex allopeptides induces donor-specific unresponsiveness to renal allografts. Transplantation, 56: 461-465. PMID: 7689263

Schwartz, R.H., 1990. A cell culture model for T lymphocyte clonal anergy. Sci., 248: 1349-1356. DOI: $10.1126 /$ science. 2113314

Shen, X.D., B. Ke, Y. Zhai, F. Gao and R.W. Busuttil, 2005b. Toll-like receptor and heme oxygenase-1 signaling in hepatic ischemia/reperfusion injury. Am. J. Transplant., 5: 1793-1800. PMID: 15996225
Shen, X.D., F. Gao, B. Ke, Y. Zhai and C.R. Lassman, et al., 2005a. Inflammatory responses in a new mouse model of prolonged hepatic cold ischemia followed by arterialized orthotopic liver transplantation. Liver Transpl., 11: 1273-1281. PMID: 16184555

Steele, D.J., T.M. Laufer, S.T. Smiley, Y. Ando and M.J. Grusby et al., 1996. Two levels of help for B cell alloantibody production. J. Exp. Med., 183: 699-703. PMID: 8627185

Steinman, R.M. and M.C. Nussenzweig, 2002. Avoiding horror autotoxicus: The importance of dendritic cells in peripheral T cell tolerance. Proc. Natl. Acad. Sci. USA, 99: 351-358.DOI: 10.1073/pnas.231606698

Steinman, R.M., D. Hawiger and M.C. Nussenzweig, 2003. Tolerogenic dendritic cells. Annu Rev. Immunol., 21: 685-711. PMID:12615891

Talmage, D.W., G. Dart, J. Radovich and K. J. Lafferty, 1976. Activation of transplant immunity: effect of donor leukocytes on thyroid allograft rejection. Science, 191: 385-388. DOI: 10.1126/science. 1082167

Tang, A.L., A.W. Bingaman, E.A. Kadavil, D.B. Leeser and D.L. Farber, 2006. Generation and functional capacity of polyclonal alloantigen-specific memory CD4 T cells. Am. J. Transplant., 6: 1275-1284. PMID: 16686752

Terasaki, P.I., 2003. Humoral theory of transplantation. Am. J. Transplant., 3: 665-673. PMID: 12780557

Trzonkowski, P., M. Bieniaszewska, J. Juscinska, A. Dobyszuk and A. Krzystyniak et al., 2009. First-inman clinical results of the treatment of patients with graft versus host disease with human ex vivo expanded CD4+CD25+CD127- T regulatory cells. Clin. Immunol., 133: 22-26

Tsung, A., R. Sahai, H. Tanaka, A. Nakao and M.P. Fink et al., 2005b. The nuclear factor HMGB1 mediates hepatic injury after murine liver ischemia-reperfusion. J. Exp. Med., 201: 11351143. PMID: 15795240

Tsung, A., R.A. Hoffman, K. Izuishi, N.D. Critchlow and A. Nakao et al., 2005a. Hepatic ischemia/reperfusion injury involves functional TLR4 signaling in nonparenchymal cells. J. Immunol., 175: 7661-7668. PMID: 16301676

Turnquist, H.R., G. Raimondi, A.F. Zahorchak, R.T. Fischer and Z. Wang, 2007. Rapamycinconditioned dendritic cells are poor stimulators of allogeneic $\mathrm{CD}^{+} \mathrm{T}$ cells, but enrich for antigenspecific Foxp3+ $\mathrm{T}$ regulatory cells and promote organ transplant tolerance. J. Immunol., 178: 70187031. PMID: 17513751 
Valujskikh, A., D. Matesic, A. Gilliam, D. Anthony and T.M. Haqqi, 1998. T cells reactive to a single immunodominant self-restricted allopeptide induce skin graft rejection in mice. J. Clin. Invest., 101: 1398-1407. DOI: 10.1172/JCI893

Vella, J.P., M. Spadafora-Ferreira, B. Murphy, S.I. Alexander and W. Harmon et al., 1997. Indirect allorecognition of major histocompatibility complex allopeptides in human renal transplant recipients with chronic graft dysfunction. Transplantation, 64: 795-800. PMID: 9326400

Wang, Z., A.T. Larregina, W.J. Shufesky, M.J. Perone and A. Montecalvo et al., 2006. Use of the inhibitory effect of apoptotic cells on dendritic cells for graft survival via T-cell deletion and regulatory T cells. Am. J. Transplant., 6: 12971311. PMID: 16686754

Wang, Z., S.J. Divito, W.J. Shufesky, T. Sumpter and H. Wang et al., 2012. Dendritic Cell Therapies in Transplantation Revisited: Deletion of Recipient DCs Deters the Effect of Therapeutic DCs. Am. J. Transplant., 12:1398-1408. PMID: 22500950
Wang, Z., W.J. Shufesky, A. Montecalvo, S.J. Divito and A.T. Larregina et al., 2009. In situ-targeting of dendritic cells with donor-derived apoptotic cells restrains indirect allorecognition and ameliorates allograft vasculopathy. PLoS ONE, 4: e4940.

Worrall, N.K., W.D. Lazenby, T.P. Misko, T.S. Lin and C.P. Rodi et al., 1995. Modulation of in vivo alloreactivity by inhibition of inducible nitric oxide synthase. J. Exp. Med., 181: 63-70.

Wyburn, K.R., M.D. Jose, H. Wu, R.C. Atkins and S.J. Chadban, 2005. The role of macrophages in allograft rejection. Transplantation, 80: 1641-1647. PMID: 16378052

Zhai, Y., X.D. Shen, R.O. 'Connell, F. Gao and C. Lassman et al., 2004. Cutting edge: TLR4 activation mediates liver ischemia/reperfusion inflammatory response via IFN regulatory factor 3dependent MyD88-independent pathway. J. Immunol., 173: 7115-7119. PMID: 15585830 